\title{
AC 2010-388: STUDY ABROAD TO SEE THE WORLD AND BECOME A BETTER ENGINEER
}

\section{Kimberly Talley, Datum Engineers, Inc.}

KIMBERLY G. TALLEY, Ph.D. is a Graduate Engineer at Datum Engineers, Inc. where she works on new building design and historic preservation projects. She earned her Ph.D. in 2009 from the University of Texas at Austin where her research focus was on the assessment and rehabilitation of deteriorated concrete. She received two B.S. degrees from North Carolina State University and her M.S. from the University of Texas at Austin. Contact:

kimt@datumengineers.com

\section{Catherine Hovell, University of Texas, Austin}

CATHERINE G. HOVELL is a PhD student at the University of Texas at Austin. Her research focuses on improving design in a Texas standard concrete bridge beam. She received her MS from UT-Austin in 2007, having performed finite element analyses of a steel bridge girder system. She is also a graduate of the University of Virginia. Contact: cghovell@gmail.com

\section{Jason Stith, University of Texas, Austin}

JASON C. STITH is a PhD student at the University of Texas at Austin. His research focuses on the stability of curved I-girder bridges during construction. He previously worked for two bridge design firms in Kentucky. He received his MS and MBA in 2005 and BS in 2004 from the University of Kentucky. Contact: stithjason@mail.utexas.edu 


\title{
Study Abroad to See the World and Become a Better Engineer
}

\begin{abstract}
Good engineers are more than just talented at math and science; they can creatively solve problems. This creativity is often assisted by being sensitive to project needs, whether those needs relate to a blind pedestrian or designing a Hindu Temple in Texas. This sort of sensitivity can be purely learned from years of engineering work experience, but the newly graduated engineer would be well served to have a wide range of experiences while at university. Study abroad allows students to learn about other cultures and increase their global awareness by living and studying outside of the US. As a result of these experiences, students have an opportunity to gain an appreciation for the culture they recently experienced and then translate that world awareness to other environments. By broadening their experiences, the engineering student is better prepared to tackle challenges of a diverse workplace. Quality graduates also play a part in the ranking of engineering programs. It is the hypothesis of this study that universities with more engineering students taking advantage of study abroad opportunities have engineering programs that enjoy higher rankings. Surveying the study abroad programs at universities with top ranked engineering programs provided the data to test this hypothesis.
\end{abstract}

\section{Introduction}

Study abroad experiences are generally regarded as valuable learning opportunities. In 2005, the US Senate even passed a declaration to make 2006 the year of study abroad while lauding the many benefits of such programs ${ }^{1}$. Engineering students with study abroad experience have a unique position of joining their technical abilities with increased sensitivity to global issues. The authors' belief is that engineering students who study abroad tend to make better engineers from their increased awareness and sensitivity. Further, that such a relationship could be seen by comparing study abroad rates of engineering students to the perceived quality of program, which results in college rankings. Therefore, the following hypothesis was proposed.

\section{Hypothesis}

Universities with more engineering students taking advantage of study abroad opportunities have engineering programs that enjoy higher rankings.

\section{Procedure}

To test the hypothesis, the authors drafted a brief survey and sent it to the study abroad programs with top ranking in US News \& World Report ${ }^{2}$. This survey was approved for use by the internal review process at Datum Engineers, Inc. The survey was sent out first on December 10, 2009 and again on February 17, 2010 to non-responders. All responses received before March 15,2010 were included in the study. The ranking used for this study was for undergraduate 
programs, as most study abroad opportunities are tailored to this level of college study. Fifty schools were contacted: the top 25 engineering schools in the subcategories of those with a doctoral program and those without a doctoral program. The survey was conducted through email and requested three statistics:

1) Percentage to engineering students who study abroad out of all students who study abroad:

$$
\left\lfloor\left(S A_{\text {Eng }} / S A_{T o t}\right) \times 100\right\rfloor
$$

2) Percentage of engineering students in the total student body:

$$
\left\lfloor\left(S B_{\text {Eng }} / S B_{\text {Tot }}\right) \times 100\right\rfloor
$$

3) Percentage of student body that goes on study abroad:

$$
\left[\left(S A_{T o t} / S B_{T o t}\right) \times 100\right] \text {. }
$$

where:

$S A_{E n g}=$ Number of engineering students that studied abroad

$S A_{T o t}=$ Total number of students that studied abroad

$S B_{E n g}=$ Number of engineering majors in student body

$S B_{T o t}=$ Total number of students in student body

In cases where the survey response did not directly answer these questions, the authors used provided data to determine percentages, or, when that was not possible, left the answer blank for that school.

\section{Collected Data}

A total of 19 schools responded to the survey (response rate $=38 \%$ ). Of those 19 schools, one did not have any study abroad program, and one did not keep records of the program that existed. The responses are presented in Table 1 and Table 2, split by institution type. 
Table 1: Data collected from schools without doctoral programs

\begin{tabular}{|c|c|c|c|}
\hline Rank $^{2}$ & $\begin{array}{c}S A_{\text {eng }} / S A_{\text {tot }} \\
(\%)\end{array}$ & $\begin{array}{l}\mathbf{S B}_{\text {eng }} / \mathbf{S B}_{\text {ot }} \\
(\%)\end{array}$ & $\begin{array}{c}S \mathrm{SA}_{\mathrm{tot}} / \mathrm{SB}_{\mathrm{ot}} \\
(\%)\end{array}$ \\
\hline 2 & 90 & 87 & 2.5 \\
\hline 3 & 75 & 55 & 5 \\
\hline 5 & 17 & 35 & $<1$ \\
\hline 6 & 12 & 28 & 4.5 \\
\hline 6 & \multicolumn{3}{|c|}{ NO RECORDSKEPT } \\
\hline 8 & 100 & 100 & 25 \\
\hline 10 & 4 & 14 & 34 \\
\hline 12 & 0.1 & 4 & 5 \\
\hline 15 & \multicolumn{3}{|c|}{ NO PRO GRAMS OFERED } \\
\hline 19 & 24 & 22 & 30 \\
\hline
\end{tabular}

Table 2: Data collected from schools with doctoral programs

\begin{tabular}{|c|c|c|c|}
\hline Rank $^{2}$ & $\begin{array}{c}\mathbf{S A}_{\text {eng }} / \mathbf{S A}_{\text {tot }} \\
(\%)\end{array}$ & $\begin{array}{c}\mathbf{S B}_{\text {eng }} / \mathbf{S B}_{\text {ot }} \\
(\%)\end{array}$ & $\begin{array}{c}\mathbf{S A}_{\text {tot }} / \mathbf{S}_{\text {ot }} \\
(\%)\end{array}$ \\
\hline 2 & 12 & 22 & 50 \\
\hline 5 & & 18 & \\
\hline 7 & 13 & 41 & \\
\hline 9 & 16 & 22 & 4 \\
\hline 9 & 6 & 14 & 5 \\
\hline 14 & 7 & 17 & 33 \\
\hline 17 & 5 & 10 & 2 \\
\hline 19 & 9 & 16 & 30 \\
\hline 23 & 2 & 11 & 5 \\
\hline
\end{tabular}

The data is also presented graphically in Figure 1. The data presented in the first graph can be compared to the national average: $3.1 \%$ of students who study abroad major in an engineering discipline ${ }^{3}$. 
(1) Engineering SA Students / All SA Students

(2) Engineering Students / All Students
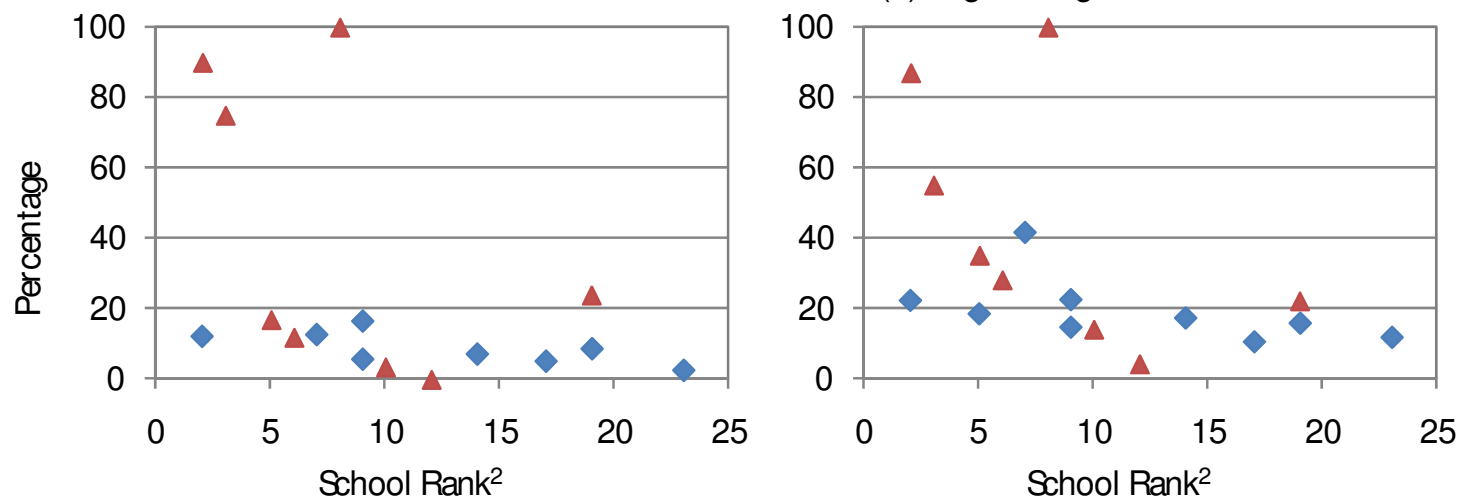

(3) All SA / All Students

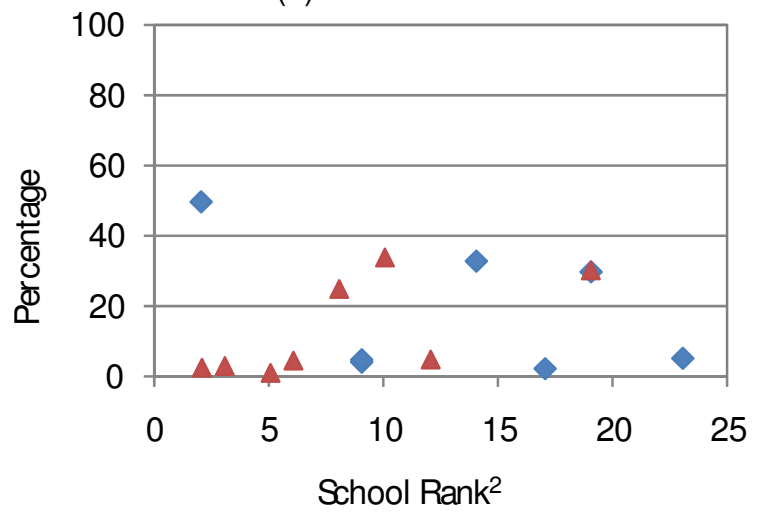

With Doctoral Programs

A Without Doctoral Programs

Figure 1: Collected data, presented graphically.

Of the respondents, which ranged in ranking from 2 to 23 , the participation of engineering students in study abroad programs (Question 1) ranged from $0.1 \%$ to $100 \%$. The percentage of engineering students in the student body (Question 2) ranged from $4.1 \%$ to $100 \%$. The percentage of study abroad participants within the full student body (Question 3) ranged from $1.0 \%$ to $50 \%$.

\section{Analysis of Collected Data}

As seen in the graphs of Figure 1, the ranking of engineering programs at academic institutions is neither closely related to the total percentage of students who study abroad (Question 3) nor to the total percentage of students who are in an engineering field of study (Question 2). Figure 2 shows the closest trendline that was seen in the data, which was observed by considering only the institutions granting doctoral degrees. The $\mathrm{R}^{2}$ value found was 0.56 , which indicates that $56 \%$ of the data variation relates to the exponential trendline. Thus, this trendline presents a modest fit to the exponential trend of higher engineering student study abroad participation to higher program rank. There was no close relationship observed between these values for the non-doctoral granting institutions $\left(\mathrm{R}^{2}\right.$ values were much less than $\left.50 \%\right)$. 
(1) Engineering SA Sudents / All SA Sudents

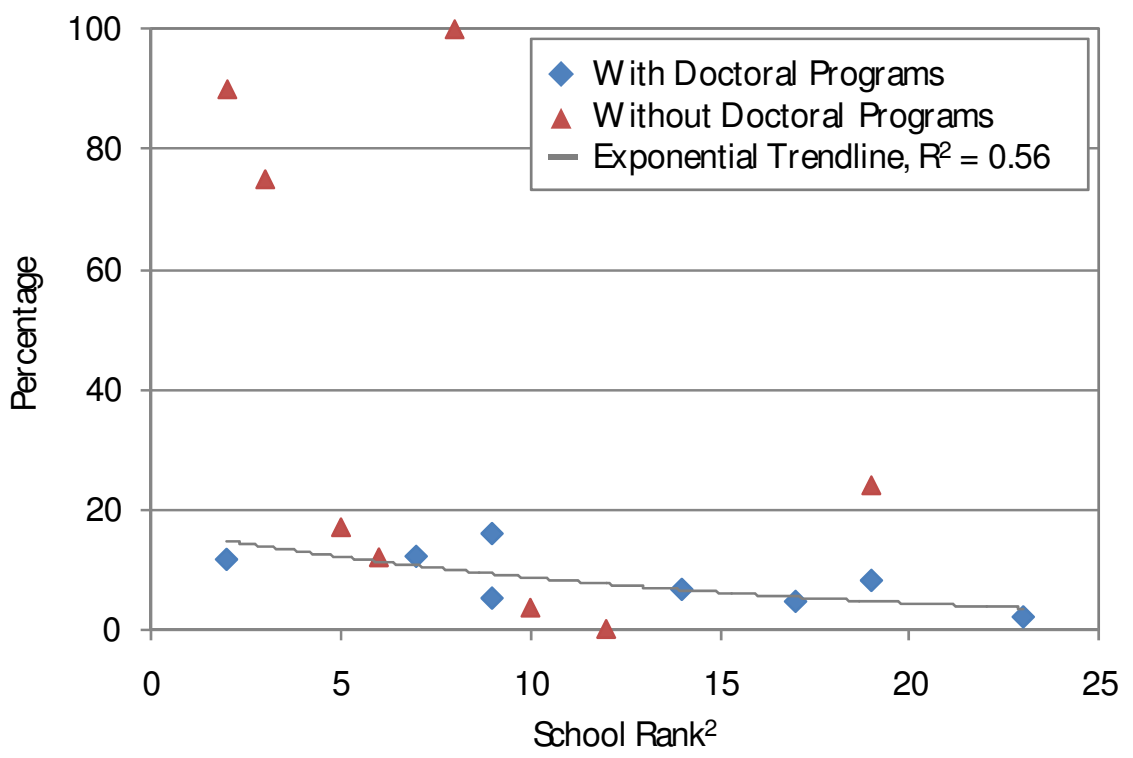

Figure 2: Participation of engineering students in study abroad programs.

The second question was included in the survey to assist in capturing the dominance of engineering on the campus of top ranked schools. The percentage of students with an engineering major out of the entire student body for the responding school is presented in Figure 3. Also included in this figure is the national average number of engineering degrees conferred in the United States, $4.4 \%{ }^{4}$. Note that there are two outlying schools with $100 \%$ or near to $100 \%$ students with engineering majors. While percentage of engineering students out of the total student body does not follow a close trendline to program rank, Figure 3 does indicate that the top ranked engineering programs appear to be at schools with more engineering students than the national average. 
(2) Engineering Students / All Sudents

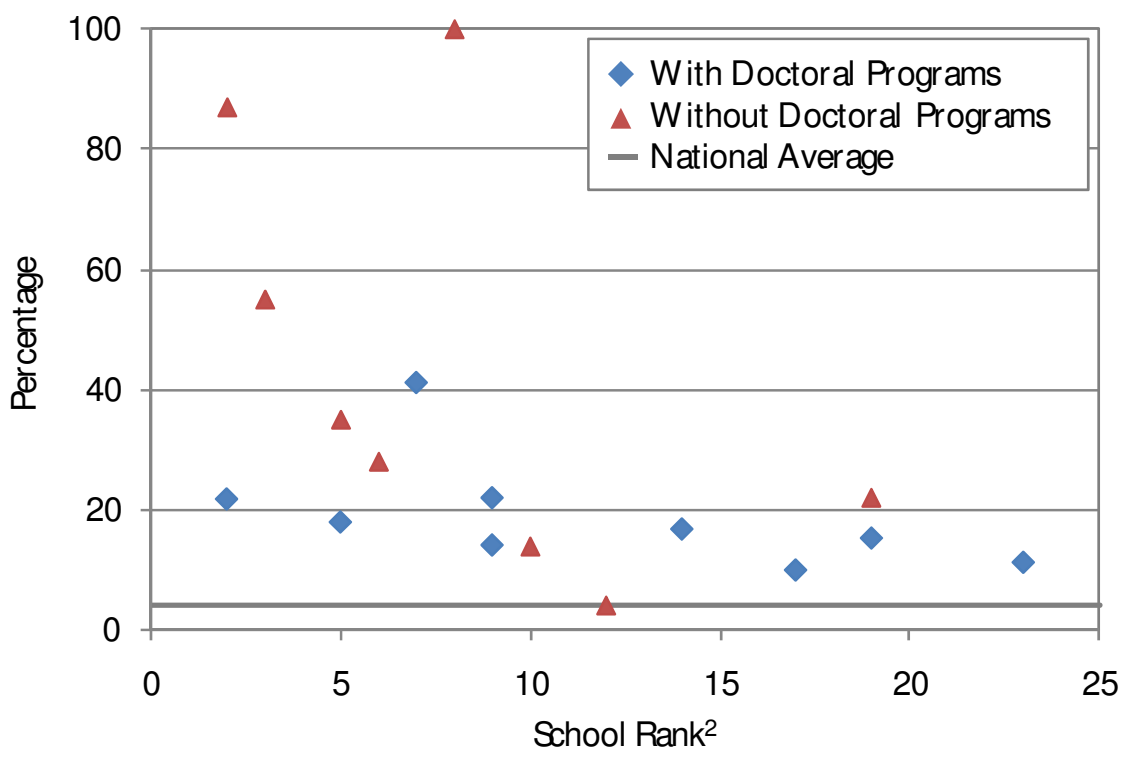

Figure 3: Percentage of engineering students within the student body.

The final piece of data collected was the percent of the student body that studies abroad. This gave the authors a sense of the importance placed on study abroad by the university community as a whole for each participating institution. Figure 4 is a graph of the data collected from the third question for participating schools comparing their rank and their student body participation rate. Again, no significant trends are seen, implying that university-wide study abroad rates to not necessarily influence engineering program rank.

(3) All Study Abroad Participants / All Sudents

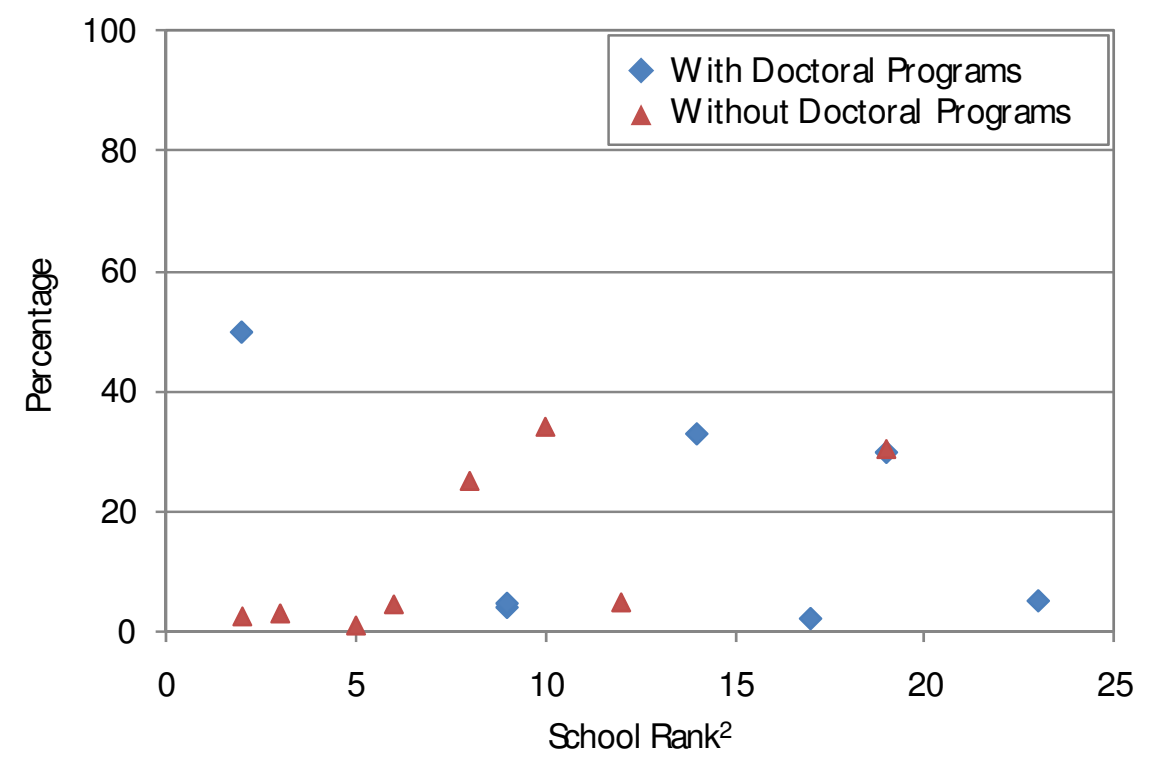

Figure 4: Percentage of study abroad students in the entire student body. 
Another way to analyze the data in order to further test the hypothesis is to factor in the size of the engineering student body into the study abroad figures. As discussed $3.1 \%$ of the study abroad participates nationally are engineering majors and $4.4 \%$ of all undergraduates students nationally major in engineering ${ }^{3,4}$. To account for the difference in engineering majors at various universities, the collected data was used to determine a new statistic for each school.

The normalized participation is calculated as the percentage of students in an engineering program at a given school who participate in study abroad, or multiplying the responses from Questions 1 and 3, then dividing by Question 2:

$$
\left[\frac{\left(S A_{E n g} / S A_{T o t}\right) \times\left(S A_{\text {Tot }} / S B_{\text {Tot }}\right)}{\left(S B_{\text {Eng }} / S B_{\text {Tot }}\right)}\right]=\left(S A_{\text {Eng }} / S B_{\text {Eng }}\right)
$$

The results of this calculation are presented for the responding institutions in Figure 5. An equivalent average was computed for the nation, as well, using the same formula: $3.1 \%$ of study abroad participants are engineers ${ }^{3} ; 3.1 \%$ of enrolled undergraduate students study abroad in a given year ${ }^{3,4}$; and $4.4 \%$ of students graduating receive an engineering degree ${ }^{4}$. The normalized average that results is $2.2 \%$. The data presented in Figure 5 shows no significant correlation between the normalized level of study abroad participation and the national ranking by the US News and World Report. While the trendline from the raw data (Figure 2) suggests support of the hypothesis, the lack of correlation fails to prove it. However, as the number and percentage of students who study abroad increases the correlation may become stronger.

Corrected Participation Values

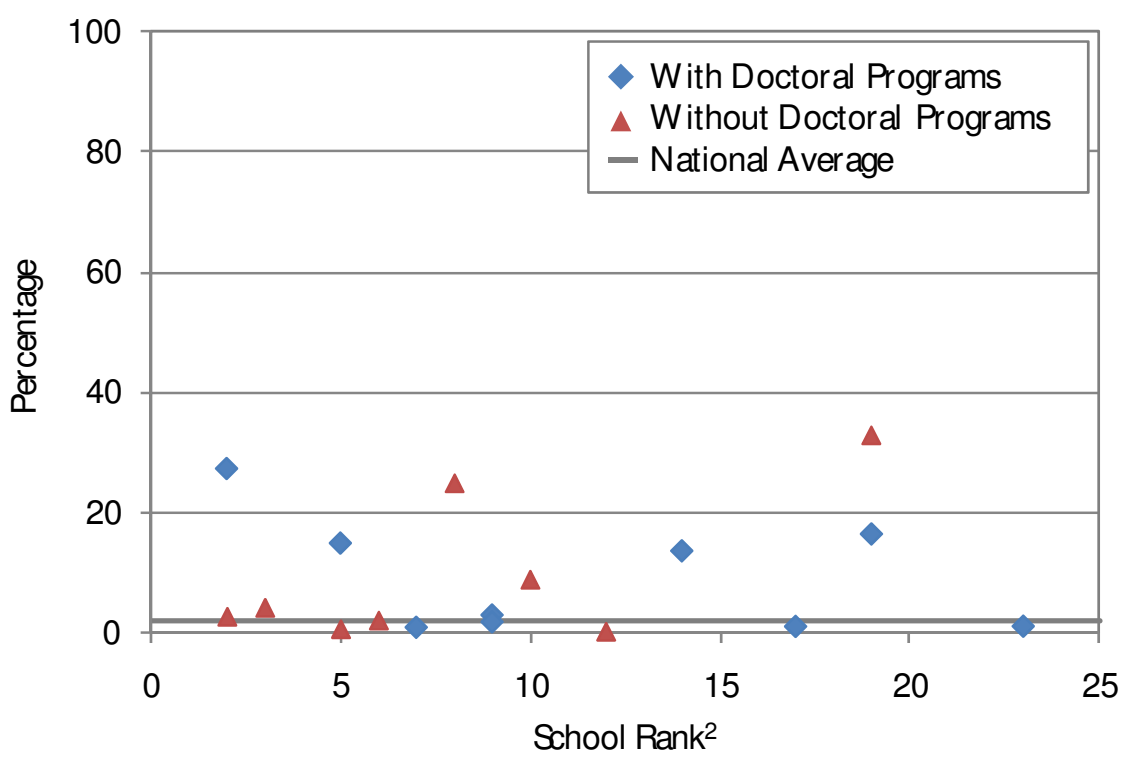

Figure 5: Participation of engineering students in study abroad programs as related to size of engineering student body. 
One potential explanation for the apparent underrepresentation of engineering students in study abroad programs at top universities would be the rigorous demands placed on those students. In a less rigid academic program, a student might have more opportunity to take a semester off without losing time on his or her progress towards graduation. This point was made by several respondents and also seen in several papers on the topic ${ }^{5,6,7}$. As such, summer programs or nontraditional, non-credit international experience such as Engineers Without Borders can be more popular with engineering students.

The responding institutions had varying amounts of students who studied abroad, but it should be noted that studying abroad has many definitions including semester- and year-long programs as well as short programs with week-long trips to foreign countries. The responds varied with their definition, but as much as possible the authors tried to be consistent providing numbers for traditional semester- or year-long study abroad programs.

Additionally, the framework of this paper and the hypothesis was formed from the experience of the authors. The authors of this paper all had different study abroad experience that ran the gamut of traditional to non-traditional. One author participated in a traditional semester-long study abroad program in Australia as well as a semester-at-sea, where he was able to earn graduate credit. Another author had a non-traditional, non-credit trip with a group of engineering students to see the famous bridges of Switzerland and tour both a national and private engineering laboratory. The final author also had two opportunities to study abroad: one summer program taking liberal arts classes in Oxford, England and taking two graduate level courses in earthquake engineering in Pavia, Italy.

\section{Conclusion}

The authors feel that in this globally connected world that an understanding of other cultures and people is critical to our success as a nation and people. The experience gained during one of these life altering study abroad programs cannot be duplicated in a classroom or lecture, but must be experienced by the individuals fortunate enough to have the opportunity.

The study presented in this paper was conducted to test the hypothesis: universities with more engineering students taking advantage of study abroad opportunities have engineering programs that enjoy higher rankings. To do so, surveys were sent to the top 25 institutions with and without doctoral programs, as currently ranked by US News and World Reports ${ }^{2}$; a total of 19 responded (with 2 responding they had no program to report on). The data gathered from these institutions were presented in tabular and graphical form. A normalization metric was used attempt to remove the bias relating percentage of engineering students in the student body to participation in study abroad programs. 
Conclusions to be drawn from this study include:

- There is only modest support of a correlation between increased study abroad participation and increased engineering program rankings;

- Engineering students are underrepresented within university study abroad programs;

- Several schools noted the recent increase in short programs and other alternative study abroad experiences (Engineers without Borders, etc.); and

- Due to the rigorous schedule of engineering students, the trend toward short programs and summer study abroad opportunities may be the most appropriate focus of study abroad offices and administrators looking to attract engineers.

The observed trending did lend some support to, but did not substantiate, the hypothesis. The inclusion of alternative study abroad programs would likely have increased the observed percentage of participation among engineering students. This change in participation level could be examined for additional support of the hypothesis. Further, the authors believe such experiences are valuable to engineering students and recommend participation in all types of study abroad programs.

\section{Bibliography}

1. A resolution designating 2006 as the "Year of Study Abroad", United States Senate Resolution 308, November $10,2005$.

2. U.S. News \& World Report, “2009 Undergraduate Engineering Program Ranking”, Sep. 2009, Vol. 146 Issue 8, p100-100, 1p.

3. Institute of International Education, Open Doors 2009 Report on International Educational Exchange, Table 22: Field Study of US Stud Abroad Students, 1998/99-2007/08.

4. Institute of Education Sciences U.S. Department of Education National Center for Education Statistics Digest of Education Statistics Table 271: Bachelor's degrees conferred by degree-granting institutions, be field of study: Selected years, 197-71 through 2006-07.

5. Fry, Cynthia, "The development of a summer study abroad program for engineering and computer science students at Baylor University," Proceedings $-34^{\text {th }}$ Annual Frontiers in Education Conference, October 2004.

6. Welker, Andrea and Lance Kenney, "Study abroad at Villanova: Analysis of an evolving program," Proceedings - 114 ${ }^{\text {th }}$ Annual ASEE Conference and Exposition, June 2007.

7. Eisenberg, Solomon, Jo-Ann Murray, and Urbain DeWinter, “Assessment of an engineering study abroad program: Reflections from the first 124 students (2001-2006)," Proceedings $-144^{\text {th }}$ ASEE Annual Conference and Exposition, June 2007. 